\title{
DESAIN MEDIA PEMBELAJARAN MATEMATIKA BERBASIS WEBSITE
}

\author{
$\operatorname{Aisyah}^{1}$ \\ Dosen Program Studi Pendidikan Matematika, FKIP, Universitas Batanghari, Jambi ${ }^{1}$ \\ e-mail: aisyah@unbari.ac.id
}

\begin{abstract}
ABSTRAK
Pembelajaran berbasis website merupakan suatu kegiatan pembelajaran yang memanfaatkan media situs (websitesite) yang bisa di akses melalui jaringan internet. Media Pembelajaran matematika berbasis website atau yang dikenal juga dengan "website based learning" merupakan salah satu jenis media pembelajaran elektronik (e-learning). Tingginya angka pengguna sarana elektronik dan jaringan internet di Indonesia membuat kebutuhan pembelajaran khususnya matematika semestinya mengikuti tren penggunaan elektronik dan jaringan internet tersebut. Penelitian ini bertujuan untuk mengembangkan media pembelajaran matematika berbasis website. Metode Penelitian yang dilakukan adalah penelitian dan pengembangan (Research \& Development) atau R\&D model 4D (Define, Design, Development and Dissemination). Namun dalam penelitian ini, baru dilakukan sebatas dua langkah yang pertama dan kedua (tahap define dan desain). Penelitian ini telah menghasilkan desain media pembelajaran matematika berbasis website yang menggunakan CMS Joomla 3.9.
\end{abstract}

Kata kunci :

Media Pembelajaran, Matematika, Websitesite.

\section{ABSTRACT (TNR 11pt)}

Website-based learning is a learning activity that utilizes website media that can be accessed through the internet. Website-based mathematics learning media or also known as "website-based learning" is one type of electronic learning media (e-learning). The high number of users of electronic facilities and internet networks in Indonesia makes learning needs, especially mathematics, should follow the trends in the use of electronics and internet networks. This research aims to develop website-based mathematics learning media. Research methods conducted are research and development (Research \& Development) or 4D R\&D models (Define, Design, Development and Dissemination). However, in this study, only the first two and two steps are done (the define and design stages). This research has resulted in the design of website-based mathematics learning media using Joomla 3.9 CMS.

Keywords :

Learning Media, Mathematics, Websitesite.

\section{PENDAHULUAN}

Perkembangan teknologi informasi begitu pesat. Asosiasi Penyelenggara Jasa Internet Indonesia (APJII) memaparkan hasil suvei bertajuk "Penetrasi dan Perilaku Pengguna Internet Indonesia 2017. Hasil survei yang berkerja sama dengan Teknopreneur itu menyebutkan, penetrasi pengguna internet di Indonesia meningkat menjadi 143,26 juta jiwa atau setara 54,7 persen dari total populasi republik ini (http://apjii.or.id). Tingginya angka pengguna internet di Indonesia juga disampaikan dalam situs kominfo.go.id bahwa Indonesia menempati peringkat ke 6 dari seluruh negara yang menggunakan internet. 


\begin{tabular}{|c|c|c|c|c|c|c|}
\hline & 2013 & 2014 & 2015 & 2016 & 2017 & 2018 \\
\hline 1. China* & 620.7 & 643.6 & 669.8 & 700.1 & 736.2 & 777.0 \\
\hline 2. US" & 246.0 & 252.9 & 259.3 & 264.9 & 269.7 & 274.1 \\
\hline 3. India & 167.2 & 215.6 & 252.3 & 283.8 & 313.8 & 346.3 \\
\hline 4. Brazil & 99.2 & 107.7 & 113.7 & 119.8 & 123.3 & 125.9 \\
\hline 5. Japan & 100.0 & 102.1 & 103.6 & 104.5 & 105.0 & 105.4 \\
\hline 6. Indonesia & 72.8 & 83.7 & 93.4 & 102.8 & 112.6 & 123.0 \\
\hline 7. Russia & 77.5 & 82.9 & 87.3 & 91.4 & 94.3 & 96.6 \\
\hline 8. Germany & 59.5 & 61.6 & 62.2 & 62.5 & 62.7 & 62.7 \\
\hline 9. Mexico & 53.1 & 59.4 & 65.1 & 70.7 & 75.7 & 80.4 \\
\hline 10. Nigeria & 51.8 & 57.7 & 63.2 & 69.1 & 76.2 & 84.3 \\
\hline 11. UK* & 48.8 & 50.1 & 51.3 & 52.4 & 53.4 & 54.3 \\
\hline 12. France & 48.8 & 49.7 & 50.5 & 51.2 & 51.9 & 52.5 \\
\hline 13. Philippines & 42.3 & 48.0 & 53.7 & 59.1 & 64.5 & 69.3 \\
\hline
\end{tabular}

\begin{tabular}{|c|c|c|c|c|c|c|}
\hline 14. Turkey & 36.6 & 41.0 & 44.7 & 47.7 & 50.7 & 53.5 \\
\hline 15. Vietnam & 36.6 & 40.5 & 44.4 & 48.2 & $\$ 2.1$ & 55.8 \\
\hline 16. South Korea & 40.1 & 40.4 & 40.6 & 40.7 & 40.9 & 41.0 \\
\hline 17. Egypt & 34.1 & 36.0 & 38.3 & 40.9 & 43.9 & 47.4 \\
\hline 18. Italy & 34.5 & 35.8 & 36.2 & 37.2 & 37.5 & 37.7 \\
\hline 19. Spain & 30.5 & 31.6 & 32.3 & 33.0 & 33.5 & 33.9 \\
\hline 20. Canada & 27.7 & 28.3 & 28.8 & 29.4 & 29.9 & 30.4 \\
\hline 21. Argentina & 25.0 & 27.1 & 29.0 & 29.8 & 30.5 & 31.1 \\
\hline 22. Colombia & 24.2 & 26.5 & 28.6 & 29.4 & 30.5 & 31.3 \\
\hline 23. Thailand & 22.7 & 24.3 & 26.0 & 27.6 & 29.1 & 30.6 \\
\hline 24. Poland & 22.6 & 22.9 & 23.3 & 23.7 & 24.0 & 24.3 \\
\hline 25. South Africa & 20.1 & 227 & 25.0 & 27.2 & 29.2 & 30.9 \\
\hline Worldwide & 2.692 .9 & $2,892.7$ & 3.072 .6 & 3.246 .3 & 3.419 .9 & $3,600.2$ \\
\hline \multicolumn{7}{|c|}{$\begin{array}{l}\text { Note: individuals of any age who use the internet from any location via any } \\
\text { device at least once per month' "excludes Hong Kong: " Forecast from Aug } \\
\text { 2014; - ". "includes countries not listed } \\
\text { Source: eMarketer, Nov } 2014\end{array}$} \\
\hline
\end{tabular}

Gambar 1: Top 25 Negara Pengguna Internet

Kendatipun begitu besarnya jumlah pengguna internet di Indonesia, namun tidak diiringi dengan perkembangan media pembelajaran yang berbasis internet.
Terlihat dari sebaran layanan yang diakses berdasarkan hasil survey APJII berikut (http://apjii.or.id) :

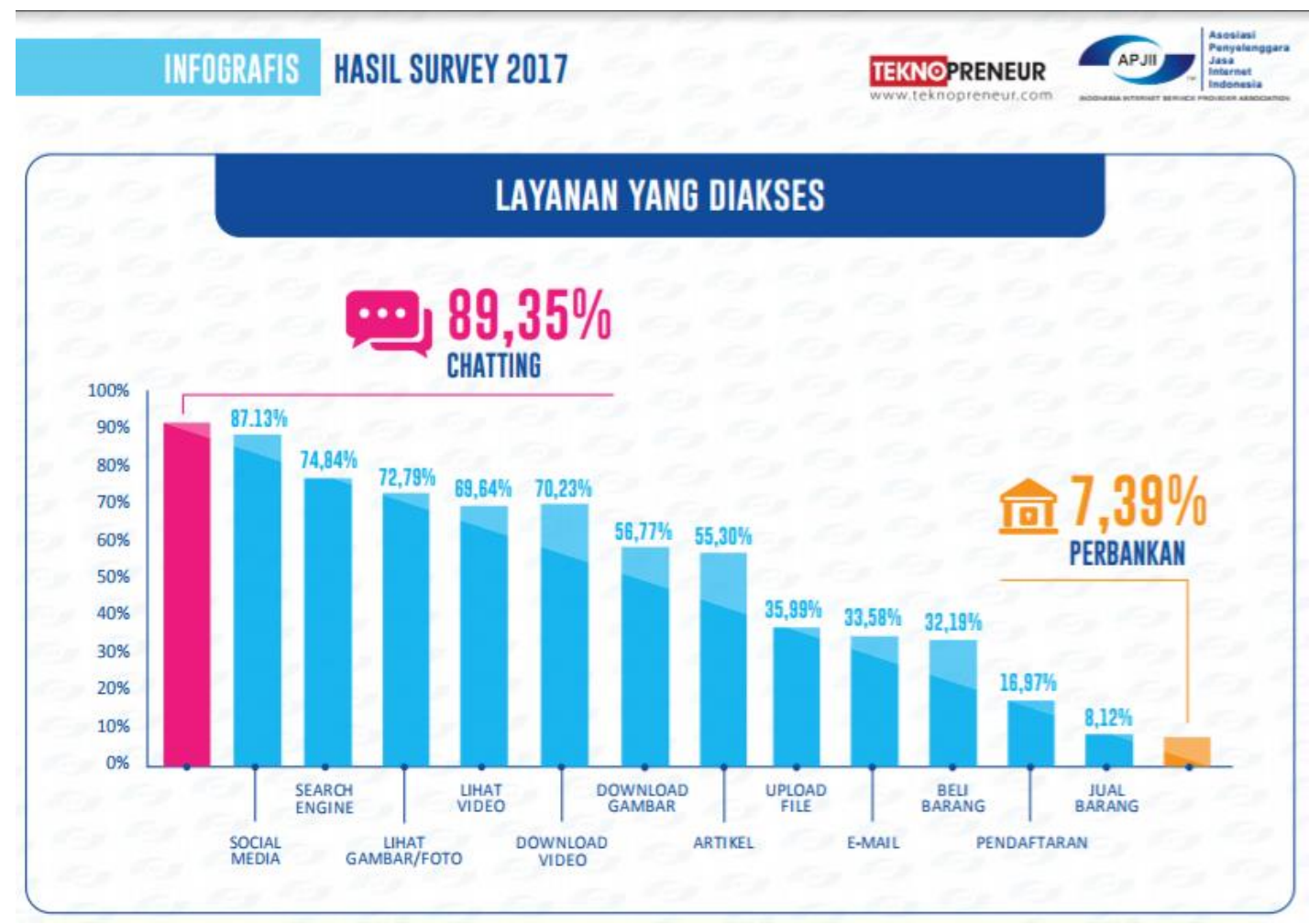

Gambar 2: Hasil Survey Layanan Internet yang Diakses Masyarakat Indonesia

Minimnya penggunaan media pembelajaran berbasis internet untuk pendidikan disebabkan banyak faktor, diantaranya sarana dan prasarana pendidikan yang masih relatif sedikit terutama untuk masuknya internet ke sekolah. Faktor lainnya yaitu SDM dalam hal ini guru maupun karyawan banyak yang masih buta terhadap internet. Tetapi faktor yang paling besar mengapa pengaksesan internet untuk pendidikan masih sangat minim adalah karena media pembelajaran berbasis websitesite sendiri masih relatif sedikit di Indonesia. Hal ini bisa disebabkan karena 


\section{$\pi$ (Phi)}

memang masih jarang pengajar yang mengembangkan media pembelajaran berbasis websitesite. Dalam hal ini khususnya pembelajaran matematika.

Banyak media yang pernah digunakan pengajar dalam memberikan materi pembelajaran matematika, seperti media presentasi powerpoint, lembar kerja, maupun dengan multimedia yang lain. Tetapi, satu kendala yang dihadapi mahasiswa adalah kurangnya waktu pembelajaran dalam kelas. Banyaknya materi baik teori maupun praktik, membuat siswa kewalahan dalam menuntaskan materi secara mendalam. Hal ini bisa diatasi salah satunya dengan menggunakan modul pembelajaran yang bisa dipelajari siswa secara mandiri berbasiskan websitesite.

Dilatarbelakangi oleh permasalahan di atas, maka diperlukan adanya sebuah media yang bisa menjadi alternatif pembelajaran bagi mahasiswa agar bisa diakses kapan saja dan di mana saja, sesuai dengan kurikulum dan dapat mengakses media lain yang diperlukan dalam pembelajaran. Oleh karena itu pada penelitian ini penulis akan menndesain sebuah media pembelajaran matematika berbasis websitesite. Adapun tujuannya adalah menghasilkan desain media pembelajaran matematika berbasis websitesite.

\section{METODE PENELITIAN}

Penelitian yang dilakukan adalah penelitian dan pengembangan (Research \& Development) atau R\&D. Metode penelitian dan pengembangan adalah metode penelitian yang digunakan untuk menghasilkan produk tertentu, dan menguji keefektifan dari produk tersebut (Sugiyono, 2009: 297).

Penelitian dan pengembangan yang digunakan adalah model 4D yang merupakan singkatan dari Define, Design, Development and Dissemination. Penelitian dan Pengembangan (R\&D) adalah metode penelitian yang digunakan untuk menghasilkan produk tertentu dan menguji keefektifan produk tersebut. Produk yang dihasilkan dari penelitian ini adalah media pembelajaran matematika berbasis website.

\section{Prosedur Pengembangan}

Model Pengembangan media yang digunakan dalam penelitian ini mengacu pada model 4-D. Model 4-D terdiri dari pendefinisian (define), perancangan (design), pengembangan (develop), dan penyebaran (disseminate) sebagaimana dikemukan oleh Thiagarajan. Tahap-tahap pengembangan media pembelajaran matematika berbasis website tersebut diuraikan sebagai berikut:

1. Tahap Pendefinisian (Define)

Tujuannnya adalah menetapkan dan menentukan syarat-syarat pembelajaran yang meliputi tujuan pembelajaran dan pembatasan materi pembelajaran.

2. Tahap Perancangan (Desain)

Pada tahap ini dihasilkan rancangan media. Tahap perancangan bertujuan untuk merancang media yang dikembangkan.

3. Tahap Pengembangan (Develop)

Pada tahap ini dihasilkan bentuk akhir media pembelajaran setelah melalui revisi berdasarkan masukkan dari para ahli dan data hasil uji coba.

4. Tahap Penyebaran (Disseminate)

Tahap ini merupakan tahapan penggunaan media pembelajaran yang telah dikembangkan dan telah diuji coba pada skala yang lebih luas. Tahap penyebaran dilaksanakan untuk menguji efektifitas media dalam kegiatan pembelajaran.

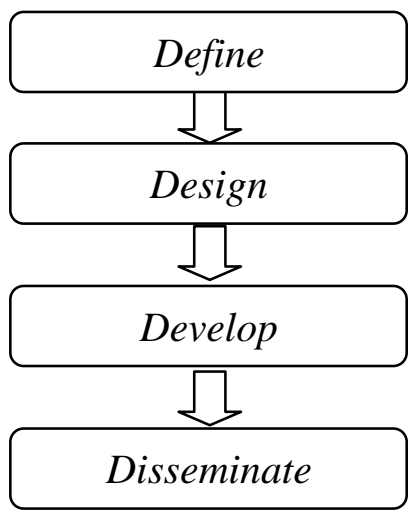

Gambar 3: Multimedia Instructional Design Process

Namun dalam prosedur pengembangan media pembelajaran berbasis website ini, baru dilakukan sebatas dua langkah prosedur 


\section{$\pi$ (Phi)}

yang pertama dan kedua (tahan define dan design).

\section{HASIL DAN PEMBAHASAN}

Penulis melakukan pengumpulan data melalui studi literatur yang dijadikan sebagai sumber website joomla. Data-data yang dikumpulkan berasal dari e-learning matematika untuk dijadikan contoh pengembangan dalam website joomla ini yang isinya berkaitan serta mendukung dalam pendesainan media pembelajaran matematika berbasis website ini. Link-link tersebut diantaranya:

a) Rumah Belajar

Beralamatkan:

http://belajar.kemdiknas.go.id/. Situs ini adalah situs resmi pemerintah untuk bidang pendidikan. Dalam situs ini terdapat berbagai macam materi yang di butuhkan dalam pembelajaran matematika.

b) Buku Sekolah Elektronik (BSE)

Beralamatkan:

http://bse.depdiknas.go.id/. Situs ini menyediakan berbagai macam buku elektronik yang bisa di akses dan di download oleh pengguna kapapun dan dimanapun.

c) Math is Fun

Beralamatkan: http://mathisfun.com/. Dalam situs ini, materi matematika di kemas dengan berbagai ilustrasi gambar yang bisa dinikmati pengguna dalam belajar matematika namun situs ini disajikan dalam bentuk bahasa inggris.

d) Bimbingan Privat Online

Beralamatkan:

http://bimbelonlineindonesia.net/. Situs ini menerima konsultasi untuk pengguna yang mau belajar privat dengan cara online. Pengguna yang mau menikmati layanan situs ini harus mendaftarkan diri sebagai anggota atau user.

e) Berlatih Operasi Hitung

Beralamatkan: http://aplusmath.com/. Situs penyedia materi matematika dalam bentuk flash ini bisa dinikmati pengguna yang suka game. Penyajian materi dengan bentuk flash secara online dan di lengkapi game matematika ini dapat di akses langsung oleh pengguna untuk berlatih matematika.

f) TV Edukasi

Beralamatkan:

http://tve.kemdikbud.go.id/. Pada situs ini, pemerintah kembali peduli untuk pendidikan Indonesia. Situs ini adalah streaming TV Edukasi yakni TV khusus untuk pendidikan anak-anak Indonesia.

Setelah mengumpulkan data-data pendukung, penulis kemudian melakukan tahapan pendesainan media pembelajaran matematika berbasis website.

\section{Tahap Pendefinisian (Define)}

a. Need Assessment

Media pembelajaran matematika berbasis websitesite masih belum menjadi media pembelajaran yang sering digunakan di Prodi Pendidikan Matematika. Dosen masih sering menggunakan media konvensional seperti modul cetak dan presentasi dengan PowerPoint.

Membuat sebuah media pembelajaran berbasis website tersedia begitu banyak frame work, CMS (Content Management System), maupun LMS (Learning Management System). Pembuatan media pembelajaran berbasis websitesite akan memanfaatkan fasilitas tersebut. Peneliti menentukan pendesainan media pembelajaran matematika berbasis websitesite ini dengan memanfaatkan CMS Joomla 3.9.

b. Front-end Analysis

Pengguna media pembelajaran matematika berbasis website yang ditargetkan adalah mahasiswa Prodi Pendidikan Matematika. Pengguna dapat memahami dasar-dasar mengoperasikan komputer dan mengetahui cara menggunakan websitesite. Sedangkan administrator media pembelajaran matematika ini adalah Dosen Pendidikan Matematika yang juga dapat mengetahui dasar-dasar pengoperasian komputer, 


\section{$\pi$ (Phi)}

mengelola website, dan mengetahui cara pengoperasian Joomla.

Selain itu teknologi yang dibutuhkan untuk pendesaianan media pembelajaran matematika berbasis website ini juga memadai dan tersedia akses internet WAN dan LAN.

\section{Tahap Design (Desain)}

Pada tahap ini yang dilakukan adalah mendesain sebuah website joomla yang merupakan media pembelajaran matematika dengan alamat Home page: localhost.matharea.com. Website ini terdiri dari beberapa menu yaitu: Home, knowledge, learning, dan About Us.

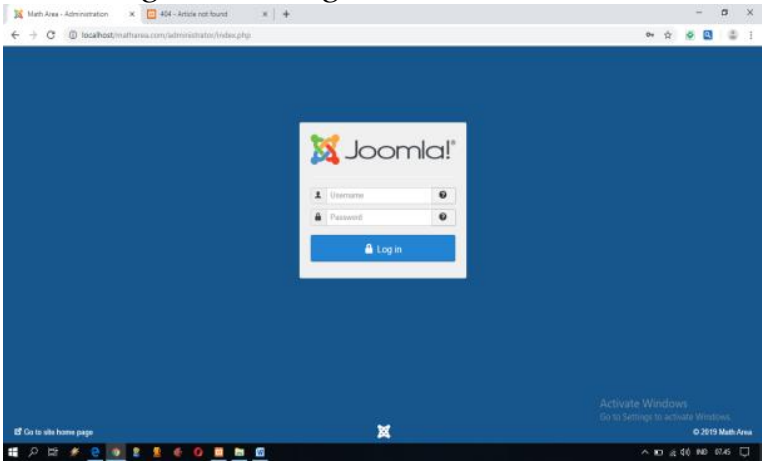

Gambar 4: Login sebagai Administrator

Membuat Storyboard dari media pembelajaran ini adalah sebagai berikut:

1) Halaman Home

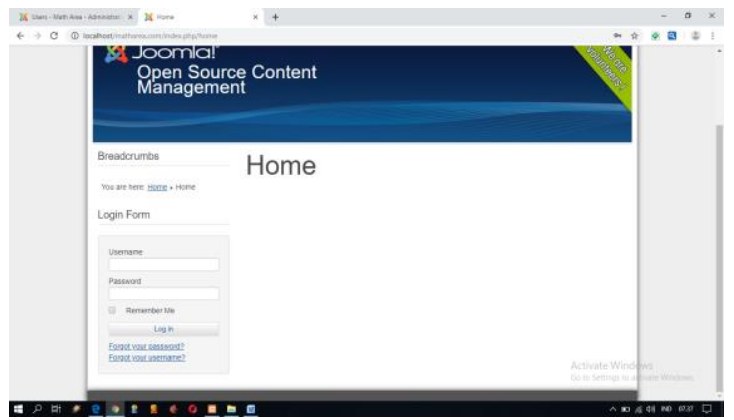

Gambar 5: Hompage Menu Home

2) Halaman Knowledge

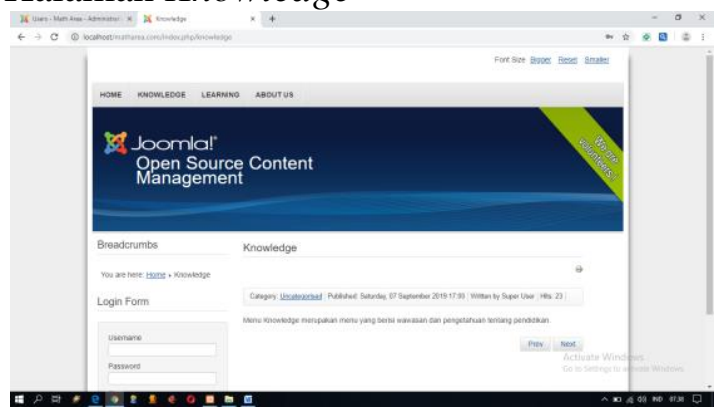

Gambar 6: Hompage Menu Knowledge

3) Halaman Learning

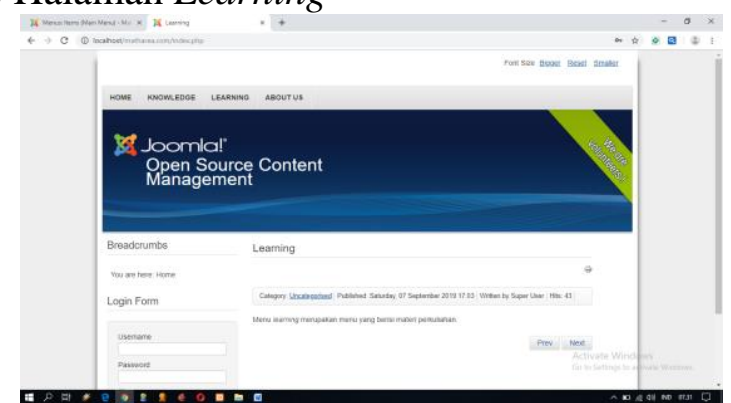

Gambar 7: Hompage Menu Learning

4) Halaman About Us

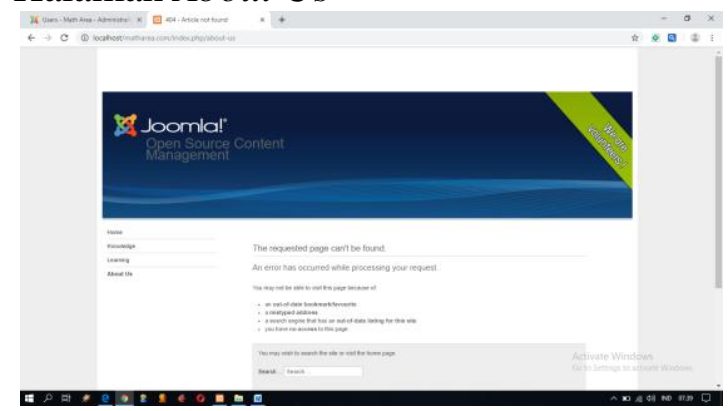

Gambar 8: Hompage Menu About Us

\section{SIMPULAN DAN SARAN}

Desain media pembelajaran matematika ini menggunakan model pengembangan Define, Design, Develop, Disseminate (4D) yaitu pendefinisian, perancangan, pengembangan, dan penyebaran. Penelitian ini hanya mengikuti langkah pertama dan kedua, yaitu tahap define: bertujuan untuk menemukan dan menetapkan masalah dasar yang dihadapi dalam pembelajaran matematika, sehingga diperlukan suatu pengembangan media pembelajaran; dan tahap Design: bertujuan untuk pemilihan pendekatan, pemilihan media pembelajaran, dan pemilihan format yang sesuai. Tahap define, memilih pengembangan media pembelajaran matematika menggunakan joomla. Tahap design, merancang (mendesain) media pembelajaran matematika menggunakan joomla dengan menambahkan homepage, Home, Knowledge, Learning, dan About Us.

Hasil penelitian ini diharapkan dapat dilanjutkan hingga tahap disseminate (penyebaran). Agar dapat mewujudkan:

1. Alternatif pilihan sumber belajar sehingga kegiatan belajar menjadi lebih bervariatif. 


\section{$\pi$ (Phi)}

2. Sumber belajar baru yang mudah dipahami dan mudah diakses.

3. Rujukan dan sumber informasi/data sekunder bagi penelitian pengembangan sejenis.

Karenanya disarankan untuk dilanjutkan dalam penelitian selanjutnya hingga ke tahap disseminasi.

\section{DAFTAR PUSTAKA}

Arikunto, Suharsimi. (2013). Dasar-Dasar Evaluasi Pendidikan (edisi 2). Jakarta: Bumi Aksara.

Arikunto, Suharsimi. (2014). Prosedur Penelitian Suatu Pendekatan Praktik. Jakarta: Rineka Cipta.

Arsyad, Azhar. (2006). Media Pembelajaran. Jakarta: PT Rajagrafindo Persada.

Asyhar, Rayandra. (2012). Kreatif Mengembangkan Media Pembelajaran. Jakarta: Referensi Jakarta.

Biehler, dkk. (2009). Target Competencies. German: eContentplus.

Cambridge Advanced Learneres Dictionary : Second Edition. (2005). Cambridge, UK : Cambridge University Press.

Djaali \& Muljono P. (2008). Pengukuran dalam Bidang Pendidikan. Jakarta: Grasindo.

Joomla. (2012). About Joomla. http://joomla.org/about-joomla.html. Dipetik 13 September 2015

Kadir, Abdul. (1999). Konsep dan Tuntunan Praktis Basis Data. Yogyakarta: Penerbit Andi.

Kemdikbud. (2016). Jumlah Data Peserta Didik Per Provinsi. Diakses dari: http://referensi.data.kemdikbud.go.id/p d_index.php. Pada tanggal 11 Juni 2018.

Kustandi, Cecep dan Bambang Sutjipto. (2011). Media Pembelajaran Manual dan Digital, Edisi Kedua. Bogor: Penerbit Ghalia Indonesia.

Lee, William W dan Diana L Owens. (2004).

Multimedia-Based
Instructional Design, Second Edition. San Fransisco: Pfeiffer.

Lewis,

J.R. (1993). IBM Computer Usability Satisfaction Questionnaires: Psychomotric Evaluation and Instrucyions for Use. Boca, Raton: IBM Corporation.

Linn, Robert L. dan Gronlund, Norman E. (1995). Measurement and Assessment in Teaching. Ohio: Prentice-Hall, Inc.

Myers, Glenford J dkk. (2012). The Art of Software Testing. New Jersey : John Wiley \& Sons, Inc.

Pressman, Roger S. (2002). Software Engineering : A Practitioner's Approach. New York : McGraw Hill Book Co.

Rusman, dkk. (2012).

Pembelajaran Berbasis Teknologi Informasi dan Komunikasi. Jakarta: Rajawali Pers.

Russeffendi. (2005). Dasar-dasar Penelitian Pendidikan Bidang Non-Eksakta \& Lainnya. Bandung: Tarsito.

Safari. (2005). Penulisan Butir Soal Berdasarkan Penelitian Berbasis Kompetensi. Jakarta: Diknas.

Simarmata, J. (2009). Rekayasa Web. Yogyakarta: Penerbit Andi.

Sugitono. (2013). Metode Penelitian Kuantitatif, Kualitatif dan $R \& D$. Bandung: Alfabeta.

Sugiyono. (2007). Memahami Penelitian Kualitatif. Bandung: Alfabeta.

Sugiyono. (2014). Metode Penelitian Pendidikan (Pendekatan Kuantitatif, Kualitatif, dan R\&D). Bandung: Alfabeta.

Suharso dan Retnoningsih, Ana. (2011). Kamus Besar Bahasa Indonesia. Semarang: Widya Karya.

Susilana, Rudi dan Cepi Riyana. 2008. Media Pembelajaran. Bandung: Jurusan Kurtekpend FIP UPI.

Wibisono, Waskitho dan Fajar Baskoro. 2002. Pengujian Perangkat Lunak dengan Menggunakan Behaviour UML. Jurnal Ilmiah Teknologi Informasi, vol. 1, No. 1, pp :43-50. 
Wahono, Romi

Satria. 2006.

Aspek

Dan Kriteria

Penilaian Media Pembelajaran.

Diakses dari

http://romisatriawahono.net/2006/06/2

1/aspek-dan-kriteria-penilaian-media-

pembelajaran/ pada tanggal 13 Mei

2018. 